\title{
CpG oligodeoxynucleotide stimulates production of anti-neutrophil cytoplasmic antibodies in ANCA associated vasculitis Plinio R Hurtado ${ }^{\dagger 1,2}$, Lisa Jeffs ${ }^{\dagger 1,2}$, Jodie Nitschke ${ }^{1,2}$, Mittal Patel ${ }^{3}$, Ghafar Sarvestani², John Cassidy², Pravin Hissaria², David Gillis² and Chen Au Peh* $* 1,2,3$
}

Address: ${ }^{1}$ Renal Unit, Royal Adelaide Hospital, North Terrace, Adelaide, 5000, Australia, ${ }^{2}$ Institute of Medical and Veterinary Science, Frome Road, Adelaide, 5000, Australia and ${ }^{3}$ The University of Adelaide, South Australia

Email: Plinio R Hurtado - plinio.hurtado@imvs.sa.gov.au; Lisa Jeffs - lisa.jeffs@student.adelaide.edu.au; Jodie Nitschke - jodie.stanley@imvs.sa.gov.au; Mittal Patel - mittal.patel@student.adelaide.edu.au; Ghafar Sarvestani - ghafar.sarvestani@imvs.sa.gov.au; John Cassidy - john.cassidy@imvs.sa.gov.au;

Pravin Hissaria - pravin.hissaria@imvs.sa.gov.au; David Gillis - david.gillis@imvs.sa.gov.au; Chen Au Peh* - chen.peh@adelaide.edu.au * Corresponding author †Equal contributors

Published: I 4 July 2008

BMC Immunology 2008, 9:34 doi:10.1 186/147/-2172-9-34
Received: 19 May 2008

Accepted: 14 July 2008

This article is available from: http://www.biomedcentral.com/147I-2172/9/34

(c) 2008 Hurtado et al; licensee BioMed Central Ltd.

This is an Open Access article distributed under the terms of the Creative Commons Attribution License (http://creativecommons.org/licenses/by/2.0), which permits unrestricted use, distribution, and reproduction in any medium, provided the original work is properly cited.

\begin{abstract}
Background: Wegener's Granulomatosis and Microscopic Polyangiitis are life-threatening systemic necrotizing vasculitides of unknown aetiology. The appearance of circulating antibodies to neutrophil cytoplasmic antigens (ANCA) is strongly associated with the development of the disease. A link between infection and disease has long been suspected, and the appearance of ANCA antibodies has been reported following bacterial and viral infections. The depletion of circulating $B$ cells with monoclonal antibody therapy can induce remission, and this observation suggests a pathogenic role for $B$ cells in this disease. As bacterial DNA is known to induce $B$ cell proliferation and antibody production via TLR-9 stimulation, we have explored the possibility that unmethylated CPG oligodeoxynucleotide, as found in bacterial and viral DNA, may play a role in stimulating circulating autoreactive $B$ cells to produce ANCA in patients with vasculitis.
\end{abstract}

Results: We have confirmed that unmethylated CPG oligonucleotide is a potent stimulator of antibody production by PBMC in vitro. The stimulation of PBMC with CPG oligonucleutides resulted in the production of similar amounts of IgG in both ANCA+ patients and normal controls. In spite of this, PR3 ANCA+ patients synthesised significantly higher amount of IgG ANCA than normal controls. In MPO ANCA+ patients, there was a tendency for patients to produce higher amount of ANCA than controls, however, the difference did not reach significance. Furthermore, we were able to detect circulating MPO-reactive B cells by ELISpot assay from the peripheral blood of $2 \mathrm{MPO}+\mathrm{ANCA}$ vasculitis patients. Together, this indicates that circulating anti-neutrophil autoreactive $B$ cells are present in ANCA+ vasculitis patients, and they are capable of producing antibodies in response to $C_{P} G$ stimulation. Of note, $C_{P}$ G also induced the production of the relevant autoantibodies in patients with other types of autoimmune diseases.

Conclusion: Circulating ANCA autoreactive B cells are present in patients with $\mathrm{ANCA}^{+}$vasculitis. The production of ANCA from these cells in response to unmethylated $C_{p} G$ stimulation lead us to propose that stimulation of these cells by immunostimulatory DNA sequences such as CPG oligodeoxynucleotide during infection may provide a link between infection and ANCA associated vasculitis. This phenomenon may also apply to other antibody mediated autoimmune diseases. 


\section{Background}

The presence of circulating anti-neutrophil cytoplasmic antibodies (ANCA) has been found to be strongly associated with the development of Wegener's Granulomatosis and Microscopic Polyangiitis [1,2], commonly known as ANCA associated vasculitis. These conditions are characterised by systemic necrotising vasculitis, arthralgia, myalgia, inflammation of the upper and lower respiratory tracts, and acute necrotising glomerulonephritis. Proteinase-3 (PR3) and myeloperoxidase (MPO) are the most common neutrophil antigens targeted $[3,4]$. Notably, ANCA specificity in these patients is directed against either PR3 or MPO but seldom both. Infrequently, other neutrophil-derived antigens such as elastase and cathepsin G can instead be targeted.

Although the pathogenic role of ANCA remains controversial, there is increasing evidence that B cells and ANCA autoantibodies are important. For example, the depletion of CD20+ peripheral B cells with Rituximab can bring about remission in patients with refractory ANCA+ vasculitis [5]. In many though not all patients, the titre of serum ANCA mirrors disease activity $[6,7]$. Furthermore, plasma exchange may have a therapeutic role [8]. An animal model of ANCA associated vasculitis has been attempted by raising antibodies to MPO in $\mathrm{MPO} /-$ knockout mice [9]. These antibodies which had been raised against MPO as a neo-antigen caused necrotizing glomerulonephritis when injected into wild type mice.

The strongest evidence for ANCA in the pathogenesis of vasculitis resides in in vitro experiments $[10,11]$. They demonstrated binding of ANCA to cytokine-primed neutrophils resulting in neutrophil activation and degranulation, with the consequent release of reactive oxygen species and inflammatory cytokines, and subsequent cellular damage to neighbouring endothelial cells.

Another potential role of circulating IgG autoantibodies in the pathogenesis of antibody-mediated autoimmune disease may be to assist $\mathrm{B}$ cells and dendritic cells in the capture of autoantigens and subsequent presentation to $\mathrm{T}$ cells, thus contributing to the development and maintenance of autoantibody production $[12,13]$.

In the case of ANCA associated vasculitis, infection has been suspected to play an important role in development of the disease. Friedrich Wegener first suggested the possible association of infection with Wegener's Granulomatosis while describing the disease $[14,15]$. Extensive studies have been carried out demonstrating the association of carriage of staphylococcus aureus in the nasal passages and Wegener's Granulomatosis [16]. This finding may be relevant to the manifestation of clinical pathology within the sinuses and the upper respiratory tract. In addition, the appearance of ANCA has been regularly reported in association with other infections such as bacterial endocarditis (anti-MPO by ELISA [17], and dual anti-MPO and PR3 by ELISA [18]), leprosy (determined by immunofluorescence only) [19], tuberculosis (mainly anti-PR3) [20], hepatitis C (anti-bactericidal/permeability increasing protein or Cathepsin G) [21], and parvovirus B19 (anti-MPO or PR3) [22].

Pendergraft and colleagues have reported that mice injected with antisense DNA-encoded PR3 generated antibodies that in turn stimulated anti-idiotypic antibodies, which recognised sense DNA-encoded PR3. Based on this phenomenon, they proposed that peptides derived from microbial organisms, which shared sequence homology with antisense DNA-encoded PR3, may serve as potential antigens to initiate autoimmunity [23].

In view of 1) the possible aetiological connection between infection and this disease, 2) the fact that Toll-like receptors (TLRs) play a critical role in the innate recognition of infectious pathogens by the immune system $[24,25] 3$ ) B cells are known to respond to viral and bacteria derived TLR-ligands such as CpG oligodeoxynucleotides, and 4) experimental evidence in murine animal models showing that TLRs are important to the development of several autoimmune disorders (reviewed in [26]), we wanted to examine the effect of TLR stimulation on the production of ANCA in vasculitis patients.

In this study, we focus on the effect of TLR stimulation, in particular the stimulation of PBMCs by the TLR-9 specific ligand single-stranded DNA with CpG motifs, CpG oligodeoxynucleotide $(\mathrm{CpG})$ as found in bacteria and viruses, to see if this agent might stimulate in vitro production of IgG ANCA from patients with ANCA+ vasculitis. CpG sequences of bacterial and viral origin are hypomethylated in contrast to mammalian DNA which is predominantly methylated. It is thought that this difference in methylation status is one of the ways by which humans avoid responding to self-DNA [26]. We chose to concentrate on TLR-9 because TLR-9 is expressed mainly by B cells and plasmacytoid dendritic cells in humans [27] and, stimulation of TLR-9 by CpG is known to induce B cell proliferation and antibody production in vitro and in vivo [28].

\section{Results \\ CPG-B induces PBMCs to produce ANCA in vasculitis patients in vitro}

PBMCs were isolated from 10 patients with biopsy-proven ANCA+ vasculitis, each paired to a normal control individual, and cultured in the presence of CpG-B and IL-2. Patient clinical details are shown in Table 1. Notably, all but one of these patients were not receiving immunosup- 
pressive medications at the time of assay. Cell culture supernatants were harvested after 12 days of culture, and concentration of IgG measured by ELISA as well as their reactivity against PR3 or MPO (Fig. 1). The supernatants from $\mathrm{PR} 3+$ and $\mathrm{MPO}+\mathrm{ANCA}$ patients were tested for reactivity against PR3 or MPO antigen respectively. We found that $\mathrm{CpG} B$ at $3.2 \mathrm{mg} \mu \mathrm{g} \mathrm{mL}-1$ to be a strong stimulant of IgG production in vitro. The amount of IgG detected in the supernatants were similar in both patient and control groups, with a concentration of $5.5 \pm 2.2$ and $4.1 \pm 1.2 \mu \mathrm{g}$ mL-1 respectively (Fig. 1A). The reactivity against PR3 and
MPO antigens in the patients' supernatants were consistently greater than those observed in normal controls. In PR3+ ANCA patients, this difference achieved significant levels $(\mathrm{P}=0.0082)$ (Fig. $1 \mathrm{~B})$. In $\mathrm{MPO}+$ patients the difference was not significant $(P=0.072)$ although their supernatants showed a clear tendency towards higher reactivity (Fig. 1C). There was no correlation between serum ANCA titre and the amount of ANCA produced in vitro $\left(\mathrm{r}^{2}=\right.$ 0.172) (Fig. 1D). In addition to CpG-B, PBMCs from 5 different pairs were also stimulated with LPS, pokeweed mitogen (PWM) or inactivated staphylococcus aureus (Fig.
A
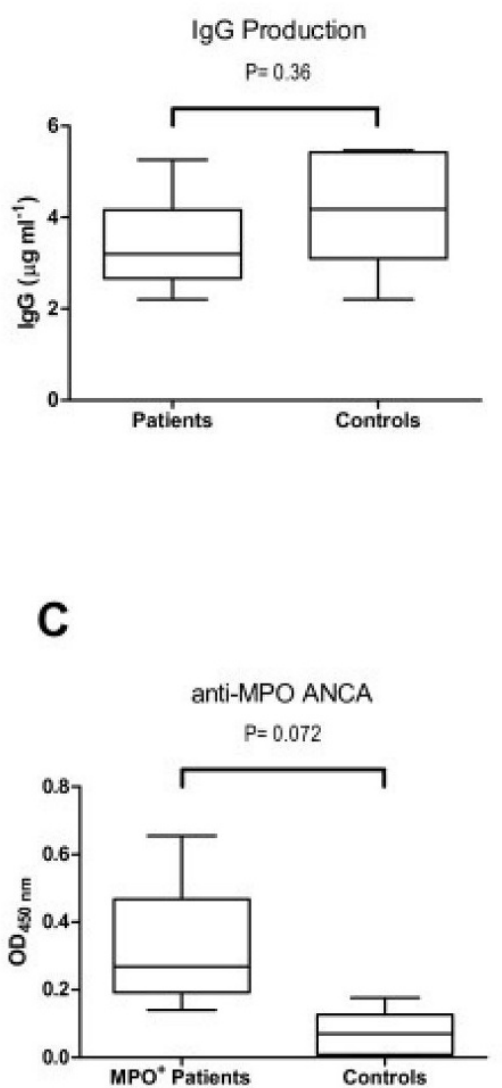

B
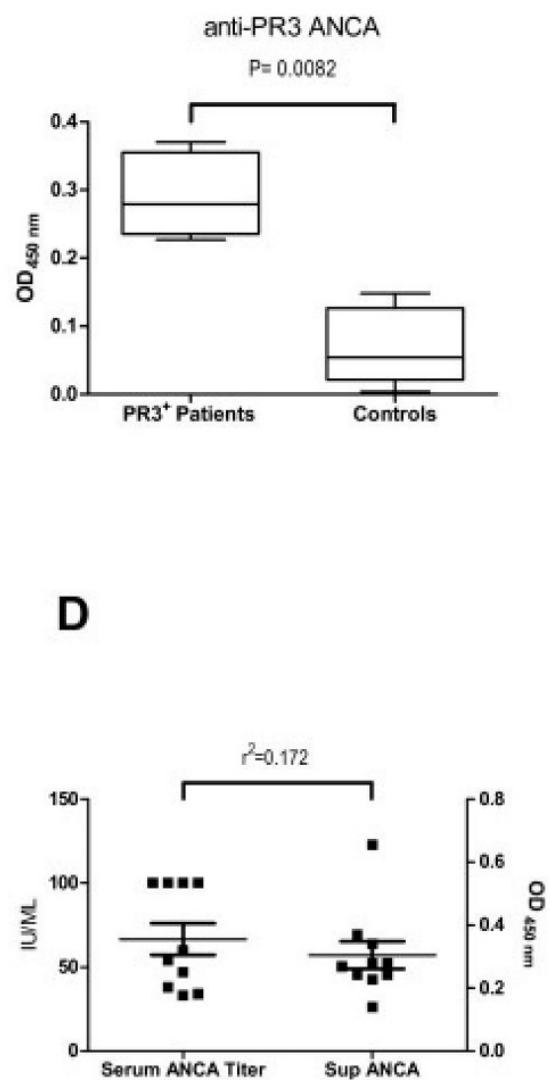

Figure I

CpG-B induces ANCA production from vasculitis patients in vitro. PBMCs isolated from patients with active ANCA associated vasculitis, $5 \mathrm{PR}^{+}$and $5 \mathrm{MPO}^{+}$ANCA patients, were cultured with $\mathrm{CpG}_{\mathrm{P}} \mathrm{B}$ and IL-2. Each patient assay was paired with a healthy control. After 12 days of culture, supernatants were harvested. IgG concentration and supernatant reactivity to either PR3 or MPO was measured by ELISA. The amount of $\lg G$ detected in the supernatants was of $5.5 \pm 2.2 \mu \mathrm{gL} \mathrm{m}^{-1}$ in the patients compared to $4.1 \pm 1.2 \mu \mathrm{g} \mathrm{mL}^{-1}$ in the control group (A). Figure B shows the reactivity of the supernatants from PR3 ${ }^{+}$ ANCA patients towards PR3 antigen. The difference against control individuals was highly significant $(P=0.0082)$. Figure $\mathbf{C}$ shows the reactivity of the supernatants from MPO+ ANCA patients towards MPO antigen. The difference was not significant $(P=0.072)$ although their supernatants showed a clear tendency towards higher reactivity compared to controls. There was no correlation between patients' serum ANCA titre at the time of the assay and their in vitro production of ANCA in response to CpG-B as shown in $\mathbf{D}\left(r^{2}=0.172\right)$. 


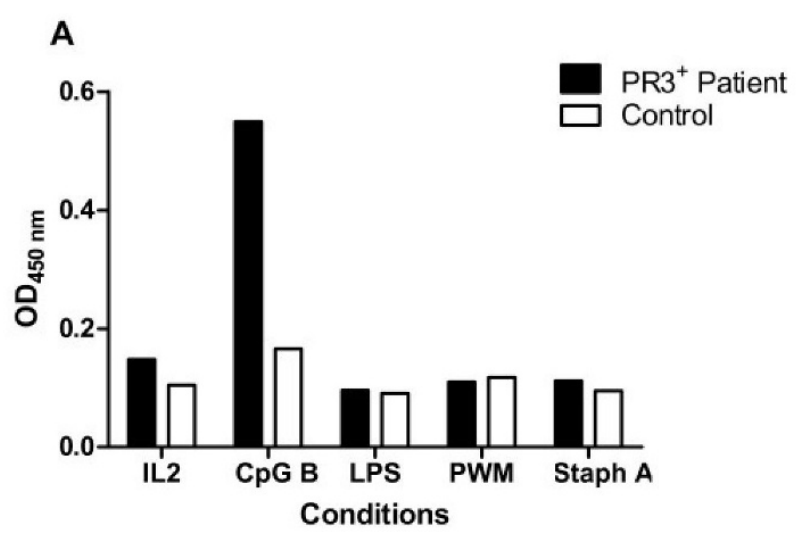

B

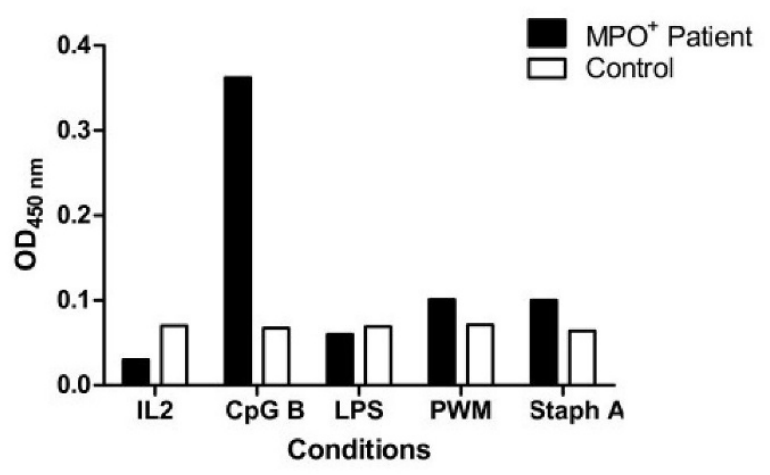

Figure 2

In vitro ANCA production is induced by CpG-B but not by other $B$ cell stimulants. In addition to $C_{p} G-B+$ IL2, PBMCs from 5 different pairs were also stimulated with either IL2 alone, LPS + IL2, pokeweed mitogen (PWM) + IL2, or inactivated staphylococcus aureus + IL2. A representative set of results is shown from a $\mathrm{PR}^{+}$ANCA patient $(\mathbf{A})$ and a MPO+ ANCA patient (B).

2). The production of IgG under these conditions was significantly lower compared to CpG-B and we were not able to detect ANCA in these conditions. The inactivated staphylococcus aureus used in these experiments had been formalin fixed. In this form, they are unlikely to provide freely available unmethylated $\mathrm{CpG}$, even though they should contain unmethylated $\mathrm{CpG}$ within.

\section{Detection of peripheral blood circulating B cells capable of producing $A N C A$ in response to $C P G-B$}

The production of ANCA autoantibodies by PBMCs in ANCA+ vasculitis patients suggested the presence of circulating ANCA autoreactive B cells in these patients. In order to test this possibility, we attempted to detect peripheral blood circulating $\mathrm{B}$ cells that are capable of producing ANCA by ELISpot. PBMCs isolated from a MPO+ ANCA patient who had had a relapse of vasculitis disease (patient no.8 in Table 1) were cultured with CpG-B and IL-2 for 5 days. Cells were then transferred into wells previously coated with either myeloperoxidase antigen or control antigen, and cultured overnight. Antibody producing cells that had produced IgG antibody against these antigens were detected by an anti-human IgG antibody. The ELISpot assay shows the presence of MPO-reactive B cells within the PBMC population of the MPO+ ANCA vasculitis patients but not of the control individuals (Fig. 3 ). Together, the above data indicate that ANCA+ vasculitis patients have in their peripheral circulation $\mathrm{B}$ cells which are capable of producing ANCA in response to CpG stimulation.

\section{CpG-B also induced production of the relevant IgG autoantibodies in patients with other autoimmune diseases in vitro}

To test if the CpG-B effect of inducing autoantibody production may be seen in other autoimmune diseases besides ANCA+ vasculitis, the same experimental procedure was performed in patients presenting with other types of autoimmune diseases, namely autoimmune thyroiditis and anti-phosphoslipid antibody syndrome. These patients were similar to most of our ANCA+ vasculitis patients in that they were not taking immunosuppressive medications at the time of study. We observed that stimulation of PBMCs with CpG-B and IL-2 led to the production of IgG anti-thyroperoxidase and anti-cardiolipin antibodies from the majority of patients with thyroiditis ( 3 out of 4 patients) and anti-phosphoslipid antibody syndrome respectively ( 2 out of 3 patients) (Fig. 4). These patients did not produce ANCA after CpG-B stimulation in vitro (data not shown).

\section{Discussion}

It is known that low affinity autoreactive B cells are part of our normal immune repertoire [29], and several studies have demonstrated the presence of circulating autoreactive $B$ cells in autoimmune diseases such as autoimmune thyroiditis [30] and systemic lupus erythematosus (SLE) [31]. In human SLE, Boumpas and colleagues have recently reported the finding of an increased number of TLR-9-expressing memory B cells and plasma cells in patients with active disease [32]. This is highly relevant to the report by Marshak-Rothstein and colleagues who had shown that co-engagement of BCR and TLR-9 by complexes of anti-DNA antibody and DNA may provide a mechanism for stimulation of autoreactive $B$ cells in lupus [33]. This demonstration becomes even more relevant given that patients with SLE have impaired DNA methylation $[34,35]$. It may also provide a tangible explanation for the beneficial effect of agents like hydroxychloroquine that inhibit TLR-9 signaling by disturbing endosomal acidification. 
Table I: Clinical and laboratory data of the patients at the time of study

\begin{tabular}{|c|c|c|c|c|c|c|}
\hline Patient Number & Age & Gender & ANCA Titre & Clinical Status & Treatment & Organ Involvement \\
\hline I & 37 & $M$ & PR3 $60 \mathrm{U}$ & Remission & Nil & $\mathrm{R}, \mathrm{J}$ \\
\hline 2 & 69 & $M$ & PR3 $34 \mathrm{U}$ & Newly Diagnosed & Prednisolone $5 \mathrm{mg} /$ day & $R, J$ \\
\hline 3 & 56 & $M$ & $\mathrm{PR} 3>100 \mathrm{U}$ & Relapse & Nil & $R, J, S, P$ \\
\hline 4 & 73 & $\mathrm{~F}$ & PR3 $>100 \mathrm{U}$ & Newly Diagnosed & Nil & $R, L, E$ \\
\hline 5 & 50 & $M$ & PR3 $33 \cup$ & Newly Diagnosed & Nil & $\mathrm{L}, \mathrm{E}, \mathrm{J}$ \\
\hline 6 & 63 & $M$ & $M P O>100 U$ & Newly Diagnosed & Nil & $R, L, C, J$ \\
\hline 7 & 77 & $M$ & MPO $54 \mathrm{U}$ & Newly Diagnosed & Nil & $R, L$ \\
\hline 8 & 67 & M & MPO $38 \mathrm{U}$ & Relapse & Nil & $R, L$ \\
\hline 9 & 57 & $M$ & MPO 47U & Relapse & Nil & $R, S, L$ \\
\hline 10 & 82 & $M$ & $M P O>100 U$ & Newly Diagnosed & Nil & $R, J$ \\
\hline
\end{tabular}

$\mathrm{R}=$ Renal, $\mathrm{E}=\mathrm{ENT}, \mathrm{L}=\mathrm{Lung}, \mathrm{C}=$ Cardiac, $\mathrm{J}=$ Joints, $\mathrm{S}=$ Skin, $\mathrm{P}=$ Peripheral Neuropathy

Similar to thyroiditis and SLE, we have also detected circulating ANCA autoreactive B cells in patients with $\mathrm{ANCA}^{+}$ vasculitis. In addition, we demonstrate that these cells are capable of producing ANCA autoantibodies in response to molecular ligands derived from bacteria and viruses such as CpG ODN. These findings provide experimental support for a link between infection and development of ANCA autoantibody.

Lanzavecchia and colleagues have reported that memory $\mathrm{B}$ cells proliferated and differentiated into antibodysecreting cells in response to $\mathrm{CpG}$ even in the absence of specific antigen stimulation [36]. They showed that CpG led to polyclonal activation of $\mathrm{B}$ cells against a range of vaccine and pathogen derived antigens, and they proposed that this microbial stimulus provided a mechanism whereby serological memory of human memory B cells is maintained. In the case of ANCA associated vasculitis, we propose a parallel mechanism, whereby microbial $\mathrm{CpG}$ ODN may contribute to the maintenance of ANCA autoreactive memory $B$ cells and ANCA autoantibody production in patients with ANCA associated vasculitis.

Our findings that CpG-B stimulates the production of the relevant autoantibodies in vitro in patients with ANCA associated vasculitis, autoimmune thyroiditis and antiphospholipid antibody syndrome suggest that this mechanism may also apply to the maintenance of autoreactive memory B cells in other antibody mediated autoimmune diseases.

Besides being the target of ANCA autoantibodies, neutrophils may also play an accessory role to drive the expansion of ANCA reactive B cells. Recently, Brinkmann and colleagues showed that activated human neutrophils release DNA to form neutrophil extracellular traps (NETs) $[37,38]$. The function of NETs is to ensnare and inactivate bacteria in defense against invading infection. Interestingly, the DNA in NETs is integrated with neutrophil anti- gens such as myeloperoxidase, elastase and cathepsin G. Given the highly cationic nature of these molecules (for example, the pI values of PR3, MPO, elastase, cathepsin G are $7.79,9.22,9.89$ and 11.3 respectively), there is a theoretical possibility that neutrophil DNA from NETs or CpG sequences derived from bacteria caught in NETs may preferentially stimulate ANCA reactive B cells by virtue of electrostatic association between negatively-charged DNA and these cationic neutrophil antigens. This may then result in preferential expansion of ANCA reactive $\mathrm{B}$ cells. For instance, highly cationic MPO may bind non-covalently to negatively charged DNA containing hypomethylated CpG sequences. After encounter with anti-MPO specific autoreactive B cells, complexes of cationic MPO/CpG may become internalised, and CpG-B may subsequently stimulate TLR-9 within endosomes. This concept is supported by a recent demonstration that internalization of BCR antigen complex triggers the fusion of endocytic vesicles with TLR-9 containing vesicles [39].

Another potential endogenous source of stimulatory CpG could be latent viruses. Lund and colleagues have shown that viral DNA from Herpes simplex virus can stimulate murine TLR-9 [40]. Since the majority of individuals harbour herpes viruses and cytomegalovirus by adulthood, and circulating viral DNA is detectable in serum, it would be relevant to see if these viruses may provide a source of hypomethylated $\mathrm{CpG}$ ODN to maintain autoreactive $\mathrm{B}$ cells in patients with ANCA associated vasculitis.

Since the first description of circulating ANCA in patients with Wegener's Granulomatosis, the vast majority of research in this field has focused on the biological functions of ANCA and whether they have a pathogenic role in disease. In contrast, much less attention has been paid to the role of ANCA specific circulating B cells in this disease. Several studies have reported the successful use of Rituximab in patients with active disease [5,41]. The clinical response to Rituximab is generally rapid. Interestingly, the 


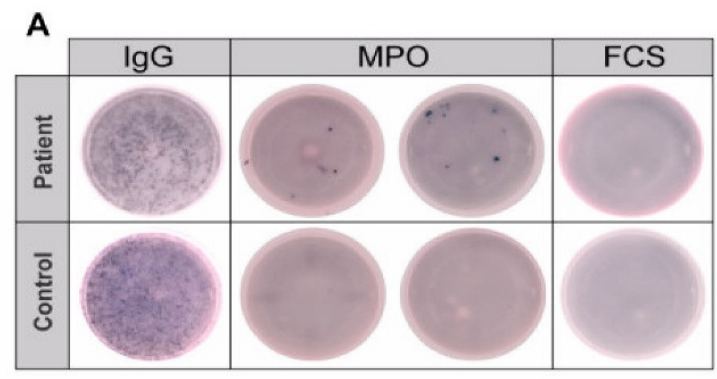

B

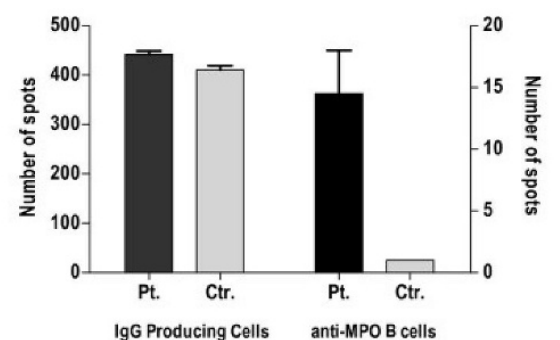

C

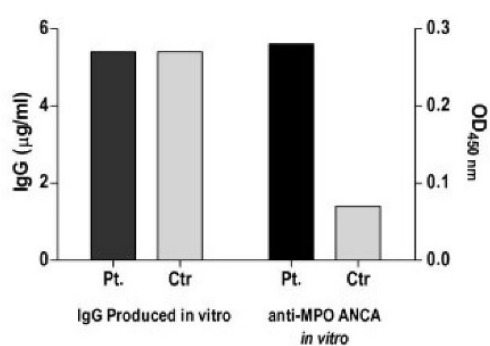

Figure 3

Detection of circulating $B$ cells capable of producing ANCA in response to CpG-B. PBMCs from $2 \mathrm{MPO}^{+}$

ANCA vasculitis patients were cultured with $C_{p}$ G-B and IL2. These PBMCs had not undergone enrichment for $B$ cells prior to culture. After 5 days culture, cells were transferred into ELISpot wells which had been coated with either myeloperoxidase (MPO) in duplicates or foetal calf serum (FCS) as a control antigen. After overnight culture, IgG antibody producing cells against these antigens were detected by antihuman $\lg G$ conjugate. The total number of $\lg G$ producing $B$ cells was measured by coating the wells with polyclonal antihuman $\lg$. The results from a patient as shown in this figure are representative of results from 2 patients. Fig $\mathbf{A}$ shows ELlspot plate with total IgG producing cells in the first column followed by the detection of anti-MPO B cells in duplicates in the middle columns and finally cells against the control antigen. The numbers of spots counted are depicted in Figure B. In spite of both patient and control having similar number of IgG producing cells, the number of anti-MPO B cells is higher in the $\mathrm{MPO}^{+}$patient. This result coincide with those from a parallel experiment where PBMCs from this pair of individuals were cultured in the presence of $C_{p} G-B$ to measure their in vitro production of anti-MPO by ELISA as shown in (C).

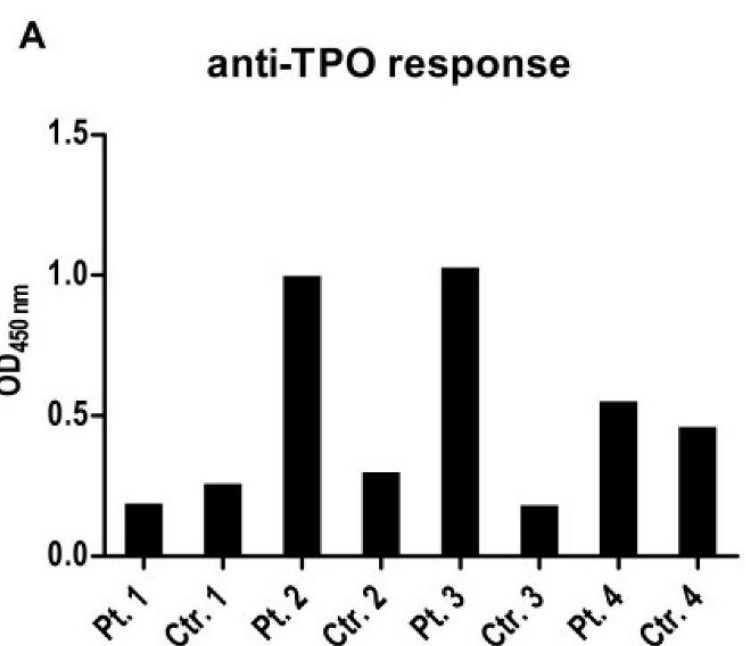

B anti-Cardiolipin response

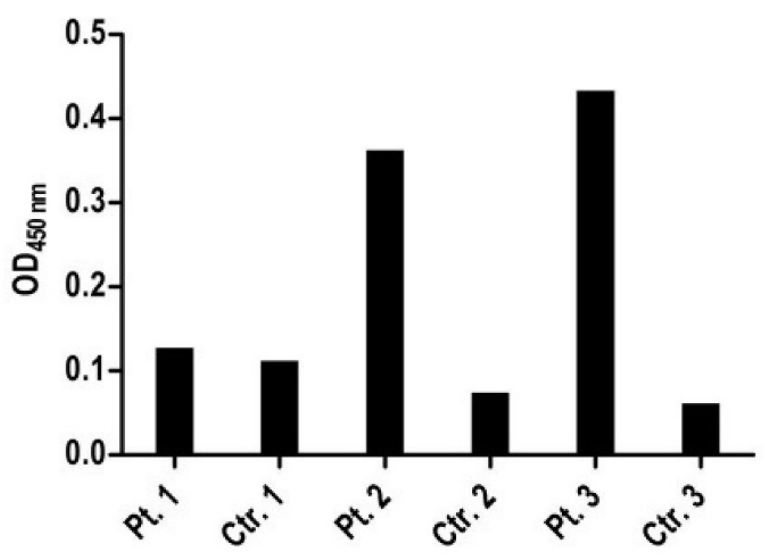

Figure 4

CPG-B also induced the production of relevant IgG autoantibodies in patients with other autoimmune diseases. PBMCs from 4 patients with autoimmune thyroiditis and 3 patients with anti-phospholipid antibody syndrome were cultured with CpG-B and IL-2. Each patient assay was paired with a healthy control. After 12 days of culture, supernatants from autoimmune thyroiditis patients were tested by ELISA for IgG anti-thyroperoxidase (TPO) as shown in $\mathbf{A}$. Supernatants from anti-phospholipid antibody syndrome patients were tested for IgG anti-cardiolipin antibodies (ACLA) as shown in $\mathbf{B}$.

clinical improvement correlates with the depletion of circulating B cells, but not immediately with the serum ANCA titre, which may remain high for much longer before decreasing. This observation makes us suspect that ANCA-specific autoreactive B cells may possess additional pathogenic roles in this disease above and beyond the 
production of ANCA autoantibodies, such as antigen presentation and cytokine production. Hence, it would be equally worthwhile to investigate if exposure of B cells to pathogen-derived $\mathrm{CpG}$ may stimulate these functions in vasculitis.

\section{Conclusion}

Circulating ANCA autoreactive B cells are present in patients with $\mathrm{ANCA}^{+}$vasculitis. These cells are able to produce measurable amounts of ANCA in vitro. This response seems to be limited to stimulation with CpG oligodeoxynucleotide, as we could not detect ANCA in response to other B cell stimulants such as LPS, pokeweed mitogen or staphylococcus aureus. These findings lead us to propose that stimulation of ANCA autoreactive B cells by immunostimulatory DNA sequences such as CpG during infection may provide a link between infection and ANCA associated vasculitis. This phenomenon may also operate in other antibody mediated autoimmune diseases. Further identification of the nature of immunostimulatory oligodeoxynucleotides and ANCA autoreactive B cells in patients may offer a greater understanding of the mechanisms by which infection is associated with development of this disease. The question of whether infection may stimulate de novo production of ANCA in individuals without vasculitis also warrants separate investigation. This possibility will need to be addressed by examining a large number of patients with different infections as the propensity to produce ANCA in response to infection may depend not only on the type of infection in question, but also on the genetic predisposition of the infected individual.

\section{Methods \\ PBMC separation and culture}

$25 \mathrm{mls}$ of peripheral blood was obtained with consent from ANCA+ vasculitis patients with biopsy proven disease. Consent was obtained in accordance to the ethical standards specified by the Royal Adelaide Hospital Human Ethics Committee. PBMC separation was performed by density gradient over LymphoprepTM (AxisShield, Oslo). After extensive washing, cells were resuspended in culture media (RPMI 1640 supplemented with $10 \%$ foetal calf serum, $2 \mathrm{mM}$ L-glutamine, $100 \mathrm{U} \mathrm{mL}^{-1}$ penicillin, $100 \mathrm{mg} \mathrm{mL}^{-1}$ gentamicin) and adjusted to a final concentration of $1 \times 10^{6}$ cells mL $\mathrm{mL}^{-1}$. Each patient sample was prepared in parallel with a control sample obtained at the same time from a healthy individual. PBMCs were stimulated with $3.2 \mu \mathrm{g} \mathrm{mL}^{-1}$ of CpG-B ODN 2006 (5'-tcgtcgttttgtcgttttgtcgtt-3'), 3.2 ug mL ${ }^{-1}$ CpG-A ODN 2216 (5'-ggGGGACGATCGTCgggggG-3'; small letters, phosphorothioate linkage; bold, CpG dinucleotides; capital letters, phosphodiester linkage $3^{\prime}$ of the base; Geneworks, Australia), IL-2 10 ng mL ${ }^{-1}$ (R\&D Systems), LPS $500 \mathrm{ng} / \mathrm{ml}$ (Sigma-Aldrich), pokeweed mitogen $3 \mu \mathrm{g}$
$\mathrm{mL}^{-1}$ (Sigma-Aldrich), inactivated staphylococcus aureus Cowan's strain (Sigma-Aldrich) or media alone. All solutions had been tested free of endotoxin. CpG was free of endotoxin $(<0.1 \mathrm{EU} / \mathrm{ml})$ while inactivated staphylococcus aureus contained $1.53 \mathrm{EU} / \mathrm{ml}$ (LAL method, Charles River PTS System). Cell culture supernatant was harvested after 12 days of culture at $37^{\circ} \mathrm{C}, 5 \% \mathrm{CO} 2$.

\section{ELISA}

Total IgG concentrations in cell culture supernatants were measured by ELISA (Bethyl Laboratories) while ANCA specificity was measured using ELISA to PR3, MPO, thyroperoxidase or cardiolipin (Orgentec, Germany). To detect IgG ANCA in supernatant, samples were diluted 1:2 and incubated for $1 \mathrm{hr}$, followed by $1 \mathrm{hr}$ with anti-human IgG conjugated to horseradish peroxidase. Enzyme activity was detected using TMB substrate, stopped with hydrochloric acid and read at $450 \mathrm{~nm}$.

\section{ELISpot}

PBMCs were cultured at $2 \times 106$ cells $\mathrm{mL}^{-1}$ in RPMI 1640 supplemented with $10 \%$ foetal calf serum, $2 \mathrm{mM} \mathrm{L}$ glutamine, $100 \mathrm{U} \mathrm{mL} \mathrm{mL}^{-1}$ penicillin, $100 \mathrm{mg} \mathrm{mL}^{-1}$ gentamicin, in the presence of CpG B $3.2 \mu \mathrm{g} \mathrm{mL}^{-1}$ and IL-2, at $37^{\circ} \mathrm{C}$ in $5 \%$ CO2 for 5 days. Twenty-four hours prior to harvesting the cells, MultiScreen HTS 96 wells plate (Millipore, France) was activated with $15 \mu \mathrm{l}$ of $70 \%$ methanol for two minutes and washed once with endotoxin-free PBS. The wells were coated with $100 \mu$ of either goat antihuman IgG (Jackson ImmunoResearch), $20 \mu \mathrm{g} \mathrm{mL}^{-1}$ of purified myeloperoxidase (Calbiochem, Germany) or $10 \%$ foetal calf serum, all diluted in carbonate/bicarbonate buffer $0.15 \mathrm{M}, \mathrm{pH}$ 9.6. The plates were washed and blocked with $100 \mu \mathrm{l}$ of complete media and incubated for $90 \mathrm{~min}$ at $37^{\circ} \mathrm{C}$. Meanwhile, cells were collected, washed $4 \times$ in complete media and adjusted to a final cell density of $2.5 \times 10^{6} \mu \mathrm{L} \mathrm{mL}^{-1} .100 \mu \mathrm{L}$ well-1 of the cell suspension was placed in the ELISpot plate in duplicate and cultured for further $12 \mathrm{hrs}$. Plates were washed with PBS and incubated with $100 \mu \mathrm{l}$ of goat anti-human IgG conjugated to alkaline phosphatase (Sigma, Germany) diluted 1:3000, at $4{ }^{\circ} \mathrm{C}$ overnight. Plates were washed and developed by adding $100 \mu \mathrm{L}$ well $^{-1}$ of BCIP/NBT Plus (Mabtech, Sweeden). The reaction was stopped at $8 \mathrm{~min}$ by rinsing the plate with running water. Plates were read by AID plate reader (Autoimmune Diagnostica, Germany).

\section{Statistics analysis}

Data are presented as means \pm standard error of the mean (SEM), and the significant differences were determined using Student's $t$ test using GraphPad Prism Software [42].

\section{Authors' contributions}

PRH, LJ, DG and CAP conceived the study, performed the experiments and wrote the manuscript. JN, MP, GS, JC 
and $\mathrm{PH}$ assisted in patient sample collection and processing.

\section{Acknowledgements}

We acknowledge the support from the Royal Adelaide Hospital Research Committee. We also thank the generosity of patients and staff of the Renal Unit.

\section{References}

I. Davies DJ, Moran JE, Niall JF, Ryan GB: Segmental necrotising glomerulonephritis with antineutrophil antibody: possible arbovirus aetiology? $\mathrm{Br}$ Med J (Clin Res Ed) 1982, 285:606.

2. van der Woude FJ, Rasmussen N, Lobatto $S$, Wiik $A$, Permin $H$, van Es LA, van der Giessen M, van der Hem GK, The TH: Autoantibodies against neutrophils and monocytes: tool for diagnosis and marker of disease activity in Wegener's granulomatosis. Lancet 1985, I:425-429.

3. Ludemann J, Utecht B, Gross WL: Detection and quantitation of anti-neutrophil cytoplasm antibodies in Wegener's granulomatosis by ELISA using affinity-purified antigen. J Immunol Methods 1988, II4:167-174.

4. Falk RJ, Jennette JC: Anti-neutrophil cytoplasmic autoantibodies with specificity for myeloperoxidase in patients with systemic vasculitis and idiopathic necrotizing and crescentic glomerulonephritis. N Engl J Med 1988, 3 18:165I-1657.

5. Keogh KA, Wylam ME, Stone JH, Specks U: Induction of remission by $B$ lymphocyte depletion in eleven patients with refractory antineutrophil cytoplasmic antibody-associated vasculitis. Arthritis Rheum 2005, 52:262-268.

6. Egner W, Chapel HM: Titration of antibodies against neutrophil cytoplasmic antigens is useful in monitoring disease activity in systemic vasculitides. Clin Exp Immunol 1990, 82:244-249.

7. Tervaert JW, Huitema MG, Hene RJ, Sluiter WJ, The TH, van der Hem GK, Kallenberg CG: Prevention of relapses in Wegener's granulomatosis by treatment based on antineutrophil cytoplasmic antibody titre. Lancet 1990, 336:709-7II.

8. Jayne DR, Gaskin G, Rasmussen N, Abramowicz D, Ferrario F, Guillevin L, Mirapeix E, Savage CO, Sinico RA, Stegeman CA, Westman $\mathrm{KW}$, van der Woude Fj, de Lind van Wijngaarden RA, Pusey CD: Randomized trial of plasma exchange or high-dosage methylprednisolone as adjunctive therapy for severe renal vasculitis. J Am Soc Nephrol 2007, 18:2 I80-2। 88.

9. Xiao H, Heeringa P, Hu P, Liu Z, Zhao M, Aratani Y, Maeda N, Falk RJ, Jennette JC: Antineutrophil cytoplasmic autoantibodies specific for myeloperoxidase cause glomerulonephritis and vasculitis in mice. J Clin Invest 2002, I I 0:955-963.

10. Falk RJ, Terrell RS, Charles LA, Jennette JC: Anti-neutrophil cytoplasmic autoantibodies induce neutrophils to degranulate and produce oxygen radicals in vitro. Proc Natl Acad Sci U S A 1990, 87:41|15-4II9.

II. Ewert BH, Jennette JC, Falk RJ: Anti-myeloperoxidase antibodies stimulate neutrophils to damage human endothelial cells. Kidney Int 1992, 41:375-383.

12. Mamula MJ, Janeway CA Jr.: Do B cells drive the diversification of immune responses? Immunol Today 1993, 14:151-2; discussion 153-4.

13. Regnault A, Lankar D, Lacabanne V, Rodriguez A, Thery C, Rescigno M, Saito T, Verbeek S, Bonnerot C, Ricciardi-Castagnoli P, Amigorena $\mathrm{S}$ : Fcgamma receptor-mediated induction of dendritic cell maturation and major histocompatibility complex class Irestricted antigen presentation after immune complex internalization. J Exp Med 1999, 189:37I-380.

14. Wegener F: Ueber generalisierte septische Gefäßerkrankungen [About generalised septic vascular diseases]. Verh Deut Pathol Ges 1936:202-10.

15. Wegener F: Ueber eine eigernartige rhinogene Granulomatose mit besonderer Beteiligung des Arteriensystems und der Nieren. Bietr Pathol Anat 1939:37-68.

16. Popa ER, Tervaert JW: The relation between Staphylococcus aureus and Wegener's granulomatosis: current knowledge and future directions. Intern Med 2003, 42:77I-780.
17. Kobayashi O, Ohtami H, Hellmich B: Anti-MPO-ANCA-positive microscopic polyangiitis following subacute bacterial endocarditis. Journal of Infection \& Chemotherapy 200I, 7:228-238.

18. Tiliakos AM, Tiliakos NA: Dual ANCA positivity in subacute bacterial endocarditis. J Clin Rheumatol 2008, 14:38-40.

19. Medina F, Camargo A, Moreno J, Zonana-Nacach A, Aceves-Avila J, Fraga A: Anti-neutrophil cytoplasmic autoantibodies in leprosy. BrJ Rheumatol 1998, 37:270-273.

20. Flores-Suarez LF, Cabiedes J, Villa AR, van der Woude F], AlcocerVarela J: Prevalence of antineutrophil cytoplasmic autoantibodies in patients with tuberculosis. Rheumatology (Oxford) 2003, 42:223-229.

21. Lamprecht P, Gutzeit O, Csernok E, Gause A, Longombardo G, Zignego AL, Gross WL, Ferri C: Prevalence of ANCA in mixed cryoglobulinemia and chronic hepatitis $\mathbf{C}$ virus infection. Clin Exp Rheumatol 2003, 21 :S89-94.

22. Hermann J, Demel U, Stunzner D, Daghofer E, Tilz G, Graninger W: Clinical interpretation of antineutrophil cytoplasmic antibodies: parvovirus B 19 infection as a pitfall. Ann Rheum Dis 2005, 64:64|-643.

23. Pendergraft WF 3rd, Preston GA, Shah RR, Tropsha A, Carter CW Jr., Jennette JC, Falk RJ: Autoimmunity is triggered by cPR$3(105-20 I)$, a protein complementary to human autoantigen proteinase-3. Nat Med 2004, 10:72-79.

24. Takeda K, Kaisho T, Akira S: Toll-like receptors. Annu Rev Immunol 2003, $21: 335-376$.

25. Medzhitov R: Recognition of microorganisms and activation of the immune response. Nature 2007, 449:819-826.

26. Krieg AM, Vollmer J: Toll-like receptors 7, 8, and 9: linking innate immunity to autoimmunity. Immunol Rev 2007, 220:25I-269.

27. Hornung V, Schlender J, Guenthner-Biller M, Rothenfusser S, Endres S, Conzelmann KK, Hartmann G: Replication-dependent potent IFN-alpha induction in human plasmacytoid dendritic cells by a single-stranded RNA virus. J Immunol 2004, 173:5935-5943.

28. Krieg AM, Yi AK, Matson S, Waldschmidt TJ, Bishop GA, Teasdale R, Koretzky GA, Klinman DM: CpG motifs in bacterial DNA trigger direct B-cell activation. Nature 1995, 374:546-549.

29. Tiller T, Tsuiji M, Yurasov S, Velinzon K, Nussenzweig MC, Wardemann $\mathrm{H}$ : Autoreactivity in human IgG+ memory B cells. Immunity 2007, 26:205-2I3.

30. Leyendeckers $H$, Voth E, Schicha $H$, Hunzelmann N, Banga $P$, Schmitz J: Frequent detection of thyroid peroxidase-specific IgG+ memory B cells in blood of patients with autoimmune thyroid disease. Eur J Immunol 2002, 32:3| 26-3/32.

31. Nicholas MW, Dooley MA, Hogan SL, Anolik J, Looney J, Sanz I, Clarke SH: A novel subset of memory B cells is enriched in autoreactivity and correlates with adverse outcomes in SLE. Clin Immunol 2008, I 26: I89-20I.

32. Papadimitraki ED, Choulaki C, Koutala E, Bertsias G, Tsatsanis C, Gergianaki I, Raptopoulou A, Kritikos HD, Mamalaki C, Sidiropoulos P, Boumpas DT: Expansion of toll-like receptor 9-expressing B cells in active systemic lupus erythematosus: implications for the induction and maintenance of the autoimmune process. Arthritis Rheum 2006, 54:360I-36II.

33. Marshak-Rothstein A: Toll-like receptors in systemic autoimmune disease. Nat Rev Immunol 2006, 6:823-835.

34. Richardson B, Scheinbart L, Strahler J, Gross L, Hanash S, Johnson M: Evidence for impaired T cell DNA methylation in systemic lupus erythematosus and rheumatoid arthritis. Arthritis Rheum 1990, 33:1665-1673.

35. Sekigawa I, Kawasaki M, Ogasawara H, Kaneda K, Kaneko H, Takasaki Y, Ogawa H: DNA methylation: its contribution to systemic lupus erythematosus. Clin Exp Med 2006, 6:99-106.

36. Bernasconi NL, Traggiai E, Lanzavecchia A: Maintenance of serological memory by polyclonal activation of human memory B cells. Science 2002, 298:2199-2202.

37. Brinkmann V, Reichard U, Goosmann C, Fauler B, Uhlemann Y, Weiss DS, Weinrauch Y, Zychlinsky A: Neutrophil extracellular traps kill bacteria. Science 2004, 303:1532-1535.

38. Fuchs TA, Abed U, Goosmann C, Hurwitz R, Schulze I, Wahn V, Weinrauch Y, Brinkmann V, Zychlinsky A: Novel cell death program leads to neutrophil extracellular traps. J Cell Biol 2007, 176:23I-24I.

39. Chaturvedi A, Dorward D, Pierce SK: The B cell receptor governs the subcellular location of Toll-like receptor 9 leading 
to hyperresponses to DNA-containing antigens. Immunity 2008, 28:799-809.

40. Lund J, Sato A, Akira S, Medzhitov R, Iwasaki A: Toll-like receptor 9-mediated recognition of Herpes simplex virus- 2 by plasmacytoid dendritic cells. J Exp Med 2003, 198:5 I3-520.

41. Eriksson P: Nine patients with anti-neutrophil cytoplasmic antibody-positive vasculitis successfully treated with rituximab. J Intern Med 2005, 257:540-548.

42. Prism GP: [http://www.graphpad.com/prism/graphing.htm].

Publish with Bio Med Central and every scientist can read your work free of charge

"BioMed Central will be the most significant development for disseminating the results of biomedical research in our lifetime. " Sir Paul Nurse, Cancer Research UK

Your research papers will be:

- available free of charge to the entire biomedical community

- peer reviewed and published immediately upon acceptance

- cited in PubMed and archived on PubMed Central

- yours - you keep the copyright

Submit your manuscript here:

http://www.biomedcentral.com/info/publishing_adv.asp 